\title{
Cytology of Infection of Maize Seedlings by Fusarium moniliforme and Immunolocalization of the Pathogenesis-Related PRms Protein
}

\author{
I. Murillo, L. Cavallarin, and B. San Segundo
}

Departamento de Genética Molecular, Instituto de Biología Molecular, Centro de Investigación y Desarrollo de Barcelona, CSIC, Jordi Girona 18, 08034 Barcelona, Spain.

Accepted for publication 2 June 1999.

\begin{abstract}
Murillo, I., Cavallarin, L., and San Segundo, B. 1999. Cytology of infection of maize seedlings by Fusarium moniliforme and immunolocalization of the pathogenesis-related PRms protein. Phytopathology 89:737-747.

We have investigated the histology of infection of maize seedlings by Fusarium moniliforme in association with a biochemical host defense response, the accumulation of the PRms (pathogenesis-related maize seed) protein. Light microscopy of trypan blue-stained sections and scanning electron microscopy revealed direct penetration by $F$. moniliforme hyphae through the epidermal cells of the seedling and colonization of the host tissue by inter- and intracellular modes of growth. Pathogen ingress into the infected tissue was associated with the induction of defense-related ultrastructural modifications, as exemplified by the formation of apposi-

in those cells types that represent the first barrier for fungal penetration such as the aleurone layer of germinating seeds and the scutellar epithelial cells of isolated germinating embryos. A highly localized accumulation of PRms within papillae of the inner scutellar parenchyma cells also occurred, suggesting that signaling mechanisms that lead to the accumulation of PRms in papillae of cell types that are distant from the invading pathogen must operate in the infected maize tissues. Our study also revealed the presence of a large number of fungal cells with an abnormal shape that showed PRms-specific labeling. PRms was found to accumulate in clusters over the fungal cell wall. Taken together, the occurrence of PRms in cell types that first establish contact with the pathogen, as well as in papillae, and in association with fungal cell walls suggests that PRms may have a function in the plant defense response.
\end{abstract} tions on the outer host cell wall surface, the occlusion of intercellular spaces, and the formation of papillae. Cellular and subcellular immunolocalization studies revealed that PRms accumulated at very high levels
Additional keywords: fungal colonization, host reactions, seed germination.
Plants are exposed to a large number of potential pathogens and, accordingly, have evolved a variety of constitutive and induced defense mechanisms. In some cases, resistance to pathogen attack can be the consequence of the molecular recognition between products of resistance $(\mathrm{R})$ genes of the host and corresponding avirulence (avr) genes of the pathogen $(13,38)$. These genetically defined resistances are, however, highly specific in nature (cultivar-race specificity). Most plants exhibit resistance to pathogenic attack as the outcome of a general defense strategy in which a wide range of biochemical responses are induced in a coordinated manner $(2,4,12$, $37)$. In contrast to genetically defined resistances, the pathogen-induced mechanisms involved in generalized disease defense responses in plants are nonspecific with respect to the pathogen that triggers their activation. All plants, including susceptible ones, respond to challenge by potential pathogens, a response that is largely dependent upon changes in gene activity. The differences between the two responses, susceptible or resistant phenotypes, might reflect differences in the speed, intensity, spatial pattern, and range of expression of different genes, the so-called defense genes. This might also account for the differences in susceptibility that are observed among different host cultivars to a particular pathogen. In line with this, manipulation of the sites and intensity of expression of plant defense genes has proven to be effective in the control of fungal pathogens $(1,6,16,23,43)$.

One of the most frequently observed biochemical events following infection by a pathogen is the transcriptional activation of pathogenesis-related (PR) genes $(4,22,41,44)$. They were first iden-

Corresponding author: B. San Segundo; E-mail address: bssgmb@cid.csic.es

Publication no. P-1999-0729-01R

(C) 1999 The American Phytopathological Society tified in leaves of tobacco plants reacting hypersensitively to tobacco mosaic virus infection $(15,26,41)$. It is typical for PR proteins to be synthesized in response to different infectious agents such as virus, viroids, fungi, and bacteria. Currently, PR proteins are grouped into 12 independent families, PR-1 to PR-12, and antifungal activities have been described for some of them. The best known examples are $\beta$-1,3-glucanases and chitinases (PR-2 and PR-3, respectively) $(17,21,34,35)$. Transgenic plants expressing chitinase and $\beta$-1,3-glucanase genes exhibit enhanced protection against fungal pathogens $(6,16,43)$.

PR-1-type proteins have been described in different plant species: tobacco, tomato, Arabidopsis thaliana, and barley $(7,15,25$, 27,40,42). However, little is known about the biological activity and function of the PR-1 family of PR proteins in the plant defense response. There are evidences indicating that PR-1 proteins may have antifungal activity. Thus, transgenic plants overexpressing a tobacco PR-1 protein have been shown to exhibit protection against two oomycete pathogens (1). Furthermore, Niderman et al. (29) reported the in vitro inhibitory activity of tomato and tobacco PR-1 proteins against Phytophthora infestans.

The fungus Fusarium moniliforme is a seed-transmitted fungus that reduces germination through seed decay, damping-off, and seedling blight in a wide range of crops through the world $(24,36)$. This is the fungus most frequently found in maize seeds. Although differences in susceptibility to infection by $F$. moniliforme have been described, resistant maize varieties have not been developed (19). Besides, seeds of a wide range of commercial maize hybrids appear to be more susceptible to colonization by $F$. moniliforme than are the topcross lines (14). However, little information is available on the mode of fungal growth, the extent of tissue colonization in the maize seedling, or the mechanisms by which the plant defends itself against the pathogen. Revealing the natural defense mechanisms that the germinating maize seed develops against $F$. 
moniliforme is of interest not only because it will increase our knowledge on the nature of plant defense response, but also because it could lead to more rational strategies for the control of this pathogen in crop species.

The effect of infection by $F$. moniliforme on the germination capability of maize (Zea mays, inbred line W64A) seeds was previously reported (10). The expression of PR genes, including the PRms (pathogenesis-related maize seed) gene, has also been described in this pathosystem $(8-11,32)$. Furthermore, a 20-base pair cis-regulatory element involved in the elicitor-responsive expression of the PRms gene has been identified (33). The maize PRms protein belongs to the PR-1 group of PR proteins, which represents one of the most abundant of the PR proteins that accumulate in infected tissues of different plant species. Nevertheless, the function of the PRms protein in the plant defense response has not been elucidated. In the current work, the effect of infection by different fungi on PRms accumulation was investigated. Furthermore, histological and cytological studies have been used to follow the progression of $F$. moniliforme infection in inoculated maize seedlings in association with the fungal-induced accumulation of the PRms protein. For this, an antiserum that specifically recognizes the PRms protein was used to determine the cellular and subcellular localization of PRms in F. moniliforme-infected tissues. Our results show that PRms accumulates in cell types that are the first to establish contact with the pathogen as well as in papillae of cells that are distant from the invading pathogen.

\section{MATERIALS AND METHODS}

Plant and fungal materials. Maize (Z. mays W64A) seeds were used as the experimental material. Fungi ( $F$. moniliforme, $F$. oxysporum f. sp. dianthi, F. culmorum, Microdochium nivale, Penicillium spp., Trichoderma spp., and Pythium spp.) were grown on potato dextrose agar (Difco Laboratories, Detroit) plates at $25^{\circ} \mathrm{C}$ until the mycelium covered the surface of the plate. Conidial suspensions were prepared as previously described (8). Seeds or isolated embryos were germinated for $20 \mathrm{~h}$ and then inoculated with a conidial suspension of the fungus to be tested $\left(50 \mu \mathrm{l} ; 10^{5}\right.$ to $10^{6}$ spores per $\mathrm{ml}$ ). Inoculated and control seeds were allowed to continue germination for the required period of time.

Preparation of protein extracts and immunoblotting. Protein extracts were prepared from maize tissues using the phosphate citrate buffer ( $84 \mathrm{mM}$ citric acid and $\left.30 \mathrm{mM} \mathrm{Na} \mathrm{HPO}_{4}\right)$ at $\mathrm{pH} 2.8$ containing 2-mercaptoethanol (14 $\mathrm{mM})$ and ascorbic acid $(6 \mathrm{mM})$ (10). Protein content was assayed by the method of Bradford (5) using the Bio-Rad dye reagent (Bio-Rad Laboratories, Richmond, CA) and bovine serum albumin (BSA) as the standard.

Immunoblots were prepared essentially according to the procedure of Towbin et al. (39). Sodium dodecyl sulfate-polyacrylamide gel electrophoresis was performed by the method of Laemmli (20) using $12 \%$ polyacrylamide gels. After electrophoresis, proteins were

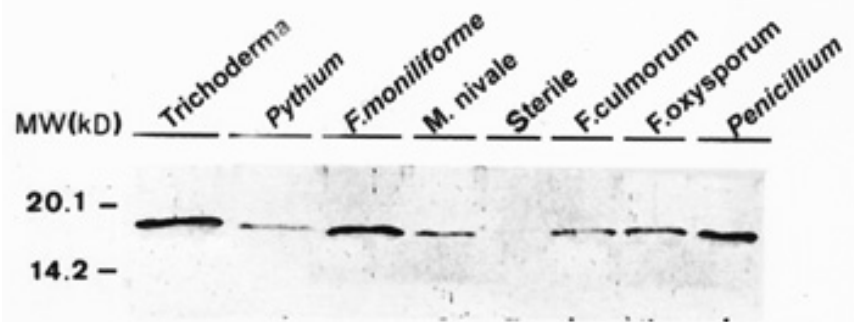

Fig. 1. PRms accumulation in fungal-infected maize tissues. Protein extracts were prepared from sterile germinating embryos and embryos that had been germinated in the presence of Trichoderma spp., Pythium spp., Fusarium moniliforme, Microdochium nivale, $F$. culmorum, $F$. oxysporum f. sp. dianthi, and Penicillium spp. Protein extracts (20 $\mu \mathrm{g}$ each) were separated on $15 \%$ sodium dodecyl sulfate-polyacrylamide gel electrophoresis gels, transferred to nitrocellulose membranes, and probed with anti-PRms antiserum. electrotransferred to nitrocellulose membranes (Hybond-N; Amersham International, Amersham, United Kingdom), blocked for $1 \mathrm{~h}$ in phosphate-buffered saline (PBS) buffer $(1 \times \mathrm{PBS}=0.05 \mathrm{M} \mathrm{Na}$ phosphate, $\mathrm{pH} 7.5$, and $0.15 \mathrm{M} \mathrm{NaCl}$ ) containing $0.1 \%$ Tween and $3 \%$ skimmed dry milk, and incubated for $1 \mathrm{~h}$ at room temperature with the diluted anti-PRms antiserum (1:1,000). Obtention and specificity of the anti-PRms antiserum has been previously described (28). After rinsing in PBS containing 0.1\% Tween 20 to remove unbound antibody, the blots were incubated for $1 \mathrm{~h}$ with swine anti-rabbit immunoglobulin ( $\mathrm{IgG}$ )-alkaline phosphatase conjugate (Dakopatts, Copenhagen, Denmark). Serological reactions were detected by the colorimetric method with nitro blue tetrazolium (NBT) and 5-bromo-4-chloro-3-indolyl phosphatase (BCIP).

Light microscopy. For light microscopy, tissues were fixed with ethanol/formaldehyde/acetic acid (80:3.5:5) for $1 \mathrm{~h}$ at room temperature. After one change, tissues were kept for 2 days in the fixation solution at $4^{\circ} \mathrm{C}$. Samples were washed twice with $70 \%$ ethanol and kept until used. The material was dehydrated through a series of ethanol solutions for $30 \mathrm{~min}$ each and embedded in paraffin (Paraplast Plus; Sigma Chemical Co., St. Louis). Sections (8 $\mu \mathrm{m}$ thick) from the paraffin-embedded material were mounted on glass slides coated with poly-L-lysine and incubated for $1 \mathrm{~h}$ in PBS buffer plus $0.05 \%$ Tween 20 (PBST) containing 3\% skimmed milk powder to block nonspecific protein-binding sites. The sections were then incubated for $2 \mathrm{~h}$ with diluted anti-PRms antiserum (1:250 in blocking buffer). After washing with PBST buffer, the sections were incubated for $1 \mathrm{~h}$ with an anti-rabbit IgG-alkaline phosphatase conjugate (Dakopatts) diluted 1:200 in blocking buffer, washed with PBST (three washes, 5 min each), and equilibrated in alkaline phosphatase buffer (100 mM Tris- $\mathrm{HCl}, \mathrm{pH} 9.5 ; 100 \mathrm{mM}$ $\mathrm{NaCl}$; and $50 \mathrm{mM} \mathrm{MgCl}_{2}$ ). Color reaction was in alkaline phosphatase reaction buffer containing $0.66 \mathrm{mg}$ of NBT per $\mathrm{ml}$ and $0.12 \mathrm{mg}$ of BCIP per $\mathrm{ml}$ and was allowed to proceed for 1 to $2 \mathrm{~h}$.

Light microscopic observations of trypan blue-stained sections were also carried out. For this, sections prepared from paraffinembedded tissues were stained with lactophenol-trypan blue (E. Merck AG, Darmstadt, Germany) for 5 min as described by Keogh et al. (18). After washing with deionized water, a drop of mounting medium (Histovitrex; Carlo Erba, Milan, Italy) was added to the slides.

Electron microscopy and immunocytochemistry. For transmission electron microscopy (TEM), tissue samples were fixed overnight at $4{ }^{\circ} \mathrm{C}$ in $2 \%$ paraformaldehyde and $0.1 \%$ glutaraldehyde in phosphate buffer $(\mathrm{PB})(1 \times \mathrm{PB}=100 \mathrm{mM}$ sodium phosphate, $\mathrm{pH}$ 7.2). After washing in $\mathrm{PB}$ (three washes, $10 \mathrm{~min}$ each), tissues were gradually dehydrated with ethanol and embedded in London Resin White (Polysciences, Inc., Warrington, PA) at $-20^{\circ} \mathrm{C}$. Sections were cut with a diamond knife, transferred to Formvarcoated nickel grids, and incubated in phosphate glycine buffer (PB plus $20 \mathrm{mM}$ glycine, $\mathrm{pH}$ 7.2). Sections were treated with PB containing $2 \% \mathrm{BSA}$ (wt/vol) for $20 \mathrm{~min}$ to prevent nonspecific binding of the antisera and then incubated for $2 \mathrm{~h}$ with the diluted antiPRms antiserum (1:200 in phosphate glycine buffer containing 1\% BSA). After three washes (5 min each) with phosphate glycine buffer, the sections were incubated for $1 \mathrm{~h}$ with goat anti-rabbit IgG conjugated to $15 \mathrm{~nm}$ of colloidal gold diluted 1:25 with phosphate glycine buffer and 1\% BSA. The sections were then washed sequentially with PB and distilled water. Ultrathin sections for TEM were subsequently poststained with freshly prepared uranyl acetate and lead citrate and examined with a H600AB Hitachi TEM (Hitachi, Tokyo, Japan) at $75 \mathrm{keV}$ accelerating potential. Controls were run in parallel using preimmune serum. Densities of labeling were determined by counting the number of gold particles per square micrometer. Area determinations were carried out by the point-counting method, using negatives of electron micrographs projected on a lattice. The density of labeling was calculated as follows: $\mathrm{Ns}=\mathrm{Ni} / \mathrm{Sa}$, in which $N s$ represents the number of gold particles per unit surface, $N i$ is the number of gold particles, and $S a$ is a specified area. 

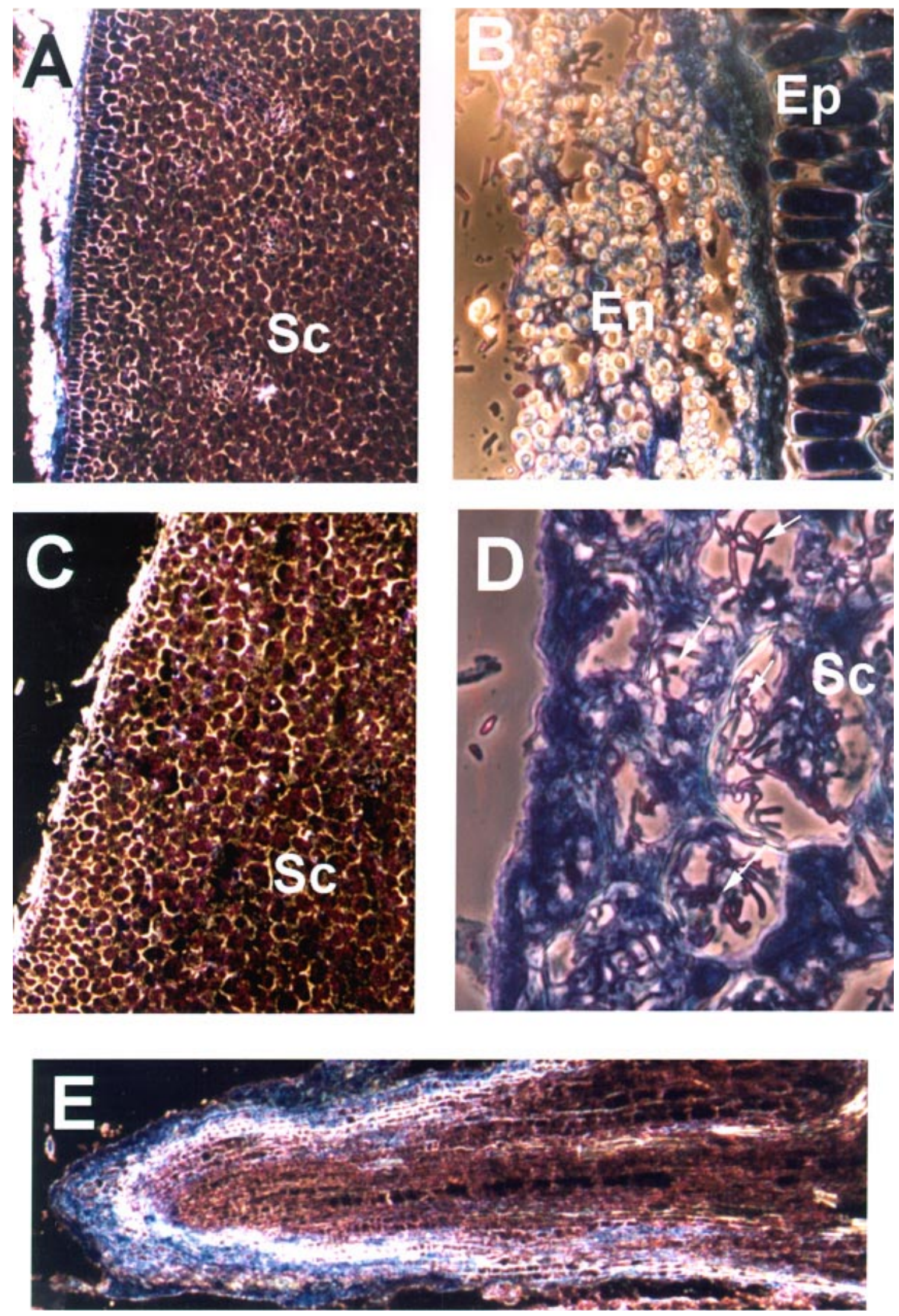

Fig. 2. Trypan blue-stained sections from A, B, D, and E, Fusarium moniliforme-infected or $\mathbf{C}$, sterile maize seedling tissues. A, Transversal section of a germinating embryo 3 days after inoculation showing the presence of numerous $F$. moniliforme hyphae (blue color) at the scutellar surface $(\times 240)$. B and $\mathbf{D}$, Fungal penetration into the scutellum takes place with a different kinetics, the level of colonization being much lower $\mathbf{B}$, in those regions where the epithelial cell layer was preserved than $\mathbf{D}$, in that of scutellar regions where the epithelial cell layer was removed. Fungal hyphae are evidenced by the blue-pink color (white arrows) $(\mathbf{B}, \times 640 ; \mathbf{D}, \times 1,600)$. C, Transversal section of a sterile 4-day-germinated embryo $(\times 240)$. E, Longitudinal section of the radicle revealed fungal colonization (blue color) at the cortical area $(\times 600)$. Ep $=$ epidermis and $\mathrm{Sc}=$ scutellum. 
For scanning electron microscopy (SEM), tissues were fixed overnight at $4{ }^{\circ} \mathrm{C}$ in $2 \%$ paraformaldehyde and $2.5 \%$ glutaraldehyde in $\mathrm{PB}, \mathrm{pH} 7.2$, rinsed with $\mathrm{PB}$, and postfixed in buffered $2 \%$ osmium tetraoxide. After rinsing, tissues were dehydrated with an ethanol series. Fixed and dehydrated samples were critical pointdried from $\mathrm{CO}_{2}$, mounted on aluminum stubs, sputter coated with palladium/platinum, and examined in H-2300 Hitachi SEM operated at $15 \mathrm{keV}$.

\section{RESULTS}

PRms accumulation in fungal-infected maize seedlings. The effect of infection by different fungi on PRms accumulation was investigated. For this, immunoblot analysis of protein extracts obtained from sterile and fungal-infected maize tissues was performed using an anti-PRms antiserum (28). Fungi that are important pathogens of maize and other cereals ( $F$. moniliforme, $F$. culmorum, and $M$. nivale), fungi with broad host range (Trichoderma spp., Penicillium spp., and Pythium spp.), and a fungus for which maize is not a natural host (F. oxysporum f. sp. dianthi) were used. The concentration of the inoculum used in this work was optimal. Higher concentrations of the inoculum drastically increased mortality of the seedlings, making biochemical and microscopical studies impossible. Thus, under these experimental conditions, the fungal-infected seeds develop symptoms of infection and are able to germinate in the presence of $F$. moniliforme. Results on the western blot analysis of protein extracts obtained from isolated germinating embryos (hereafter, embryo tissues refer to embryonic axis plus scutellum) are presented in Figure 1. Although differences in the level of immunoreactive protein among the different protein extracts were observed, all the fungi assayed in this work were able to induce PRms accumulation. This result suggests that accumulation of PRms protein could be a general response of the germinating maize seed to fungal infection.

Histological analysis of penetration and colonization by $\boldsymbol{F}$. moniliforme. A prerequisite for understanding the molecular changes that occur in a plant upon challenge with a pathogen is the cytological inspection of the fungal development in the host. Trypan blue staining has long been used in plant pathology to stain fungal hyphae, but it has also been found to stain affected plant cells around the sites of infection (18). The stain is usually excluded from healthy plant cells, and its penetration into the host cells is indicative of membrane damage. In this way, light microscopic observations of trypan blue-stained sections allowed us to monitor changes in both the pattern of fungal colonization and the morphology of cells of the infected tissue. Results are presented in Figure 2. In isolated germinating embryos, fungal hyphae growing at the surface of the scutellum were clearly visible within 48 to $72 \mathrm{~h}$ after inoculation (Fig. 2A and B). A reaction in the plant was also observed, with the scutellum outermost cell layers showing granulated protoplasts and retaining stain strongly. No such reaction was observed in sterile germinating embryos (Fig. 2C).

When dissecting the embryo from the maize seed, the structure of the epithelial cell layer cannot be entirely preserved in the scutellar tissue. A detailed examination of the trypan blue-stained sections revealed that scutellum colonization occurred earlier and seemed to progress more effectively in those regions where the structure of the epithelial cell layer was not present (Fig. 2D). Intense colonization of the tissue, with branched hyphae growing into the scutellar parenchyma cells, occurred in these regions. Furthermore, pronounced cell alterations, as judged by the extensively collapsed protoplasts of the outermost parenchyma cells of the scutellum, were observed.

The colonization of the radicle by $F$. moniliforme is shown in Figure 2E. At 3 days after inoculation, the fungus has penetrated into the cortex, but colonization of the endodermis and vascular cylinder regions was rarely observed. It is possible that the suberized layer of endodermal cells serves as a partial barrier against fungal penetration from the cortex into the central cylinder.
SEM was used to study the process of infection by $F$. moniliforme in seedling tissues. SEM micrographs obtained from intact germinating seeds revealed fungal hyphae growing on the surface of the seed pericarp. Such hyphae were capable of penetrating through the seed pericarp (Fig. 3A to C). In isolated germinating embryos, fungal ingress into the scutellum was mainly intercellular, although direct penetration into parenchyma cells also occurred (Fig. $3 \mathrm{D}$, arrows). In the radicle, the fungus penetrates directly through the epidermal cell layer (Fig. 3E).

Immunolocalization of PRms. To gain more insight into the mechanisms by which the infected maize tissues respond to pathogen attack, we have compared the histology of the infection by $F$. moniliforme with a biochemical plant defense response, the accumulation of the PRms protein. Sections obtained from sterile and $F$. moniliforme-infected maize tissues were incubated with the antiPRms antiserum. PRms accumulated in the aleurone layer of the fungal-infected seed (Fig. 4A) but not in the aleurone layer of sterile seeds (Fig. 4B). In isolated germinating embryos, intense PRmsspecific immunostaining could be observed in the scutellar epithelial cells at $24 \mathrm{~h}$ after inoculation (the shortest time analyzed here) (Fig. $4 C)$. Sterile germinating embryos did not show any labeling in the scutellum epithelial cells (Fig. 4D). Equally, no labeling was observed either in the aleurone layer or in the scutellum epithelial cells in sections treated with preimmune serum (data not shown).

A closer inspection of the sections prepared from isolated germinating embryos at a late stage of germination (5 days after inoculation with fungal spores) revealed discrete, scattered sites showing high concentrations of PRms-specific labeling at inner regions of the scutellum (Fig. 4E). Control sections incubated with preimmune serum did not show any PRms-specific immunostaining in parenchyma cells of the scutellum (Fig. 4F).

Ultrastructural aspects of fungal colonization. A more detailed analysis of the host reaction to fungal invasion was performed by electron microscopy (Fig. 5). An amorphous matrix lining the surface of the epidermal cells and surrounding fungal cells was frequently observed (Fig. 5A). The fungal cells, which are characterized by a dense cytoplasm surrounded by a thin cell wall, attached to the host wall (Fig. 5B and C). This was frequently accompanied by host wall distortions at the contact sites (Fig. 5D). In the cortical area of the radicle, mycelial growth occurred intercellularly (Fig. 5E and F), although some intracellular penetration events on the outermost cortical cell layers could also be detected (Fig. 5G). In the scutellar tissue, fungal hyphae within intercellular spaces were frequently observed (Fig. 5H).

Pathogen ingress into the infected tissue was accompanied by various host reactions such as the accumulation of material at the interface between the fungus and the host wall of colonized intercellular spaces (Fig. 5E and F). Encased hyphae that were frequently surrounded by an electron-lucent halo showed various degrees of disorganization ranging from intense vacuolation to disruption of organelles such as mitochondria to complete disintegration. In some cases, hyphae appeared to be empty shells (Fig. 5E, arrow).

The deposition of electron-opaque materials on the outer cell wall surface at the sites of fungal penetration and the formation of protuberances, known as papillae, were common host responses to infection of the scutellar parenchyma cells (Fig. 5H to J). These papillae were heterogeneous in their morphology and structure. Thus, various forms of papillae, from hemispherical or dome-like protuberances formed at the host walls to finger-like projections into the intercellular space, could be observed. Entrapment of cytoplasmic materials and organelles in papillae occurred. Furthermore, papillae developed in the absence of cell collapse and at sites distant from the penetrating pathogen.

Ultrastructural localization of PRms. Ultrathin sections were prepared from the fungal-infected maize tissues and analyzed by immunoelectron microscopy (Figs. 6 and 7). In the scutellar parenchyma cells (Fig. 6), intense PRms-specific immunolabeling in forming papillae could be detected (the density of labeling on the 
forming papillae was found to be 41 gold particles per $\mu^{2}{ }^{2}$. Although some immunoreactive material occurred at cytoplasmic regions in the proximity of the forming papillae (five gold particles per $\mu \mathrm{m}^{2}$ ), the parenchyma cell cytoplasm was nearly free of labeling $\left(0.7\right.$ gold particles per $\left.\mu \mathrm{m}^{2}\right)$ (Fig. 6 , inset). The immunoreactive material that is seen in the proximity of the forming papillae most probably correlates with PRms protein that is being targeted to this subcellular localization. Moreover, the PRms-accumulating papillae developed at sites that were not in direct contact with the penetrating pathogen. The occurrence of PRms-accumulating papillae might explain those randomly distributed sites showing high concentrations of PRms-specific labeling that were previously detected in our immunohistochemical analysis (Fig. 4E).

Furthermore, this study revealed that a large number of fungal cells located on the external surface of the infected tissues showed various degrees of cell alteration (Fig. 7A and C). Thus, the presence of highly convoluted hyphae with severe wall disruptions, as judged by the diffuse appearance of such areas and retraction of plasma membranes, were frequently observed (Fig. 7A to D). Most importantly, PRms-specific labeling was found to occur in these altered fungal cells (Fig. 7A to E). PRms was also detected in fungal cells that were in contact with the epidermal host cells (Fig. $7 \mathrm{~F}$ ), as well as in fungal cells growing into the host tissue, either inter- or intracellularly (Fig. $7 \mathrm{G}$ and $\mathrm{H}$, respectively). In all these cases, PRms labeling was found to accumulate predominantly in clusters over the fungal cell wall (densities of labeling over the cell wall and cytoplasm of the fungal cells growing on the external surface of the infected tissue were found to be 83 and 7 gold particles per $\mu \mathrm{m}^{2}$, respectively). When rabbit preimmune serum was used in place of PRms antiserum, no labeling was observed in fungal cells (Fig. 7I). Additional controls, omitting the anti-PRms serum, did not show labeling (data not shown).

However, in our plant-pathogen combination, not only the host but also the fungal cells are most likely producing activities directed to attack one to the other. This fact is illustrated in Figure 7 ( $\mathrm{J}$ and $\mathrm{K}$ ), in which wall degradation is observed in both partners, fungal and host cell walls, in those regions where they are in close contact.

\section{DISCUSSION}

The current study was undertaken to gain a better insight into the infection process of germinating maize by $F$. moniliforme in asso-
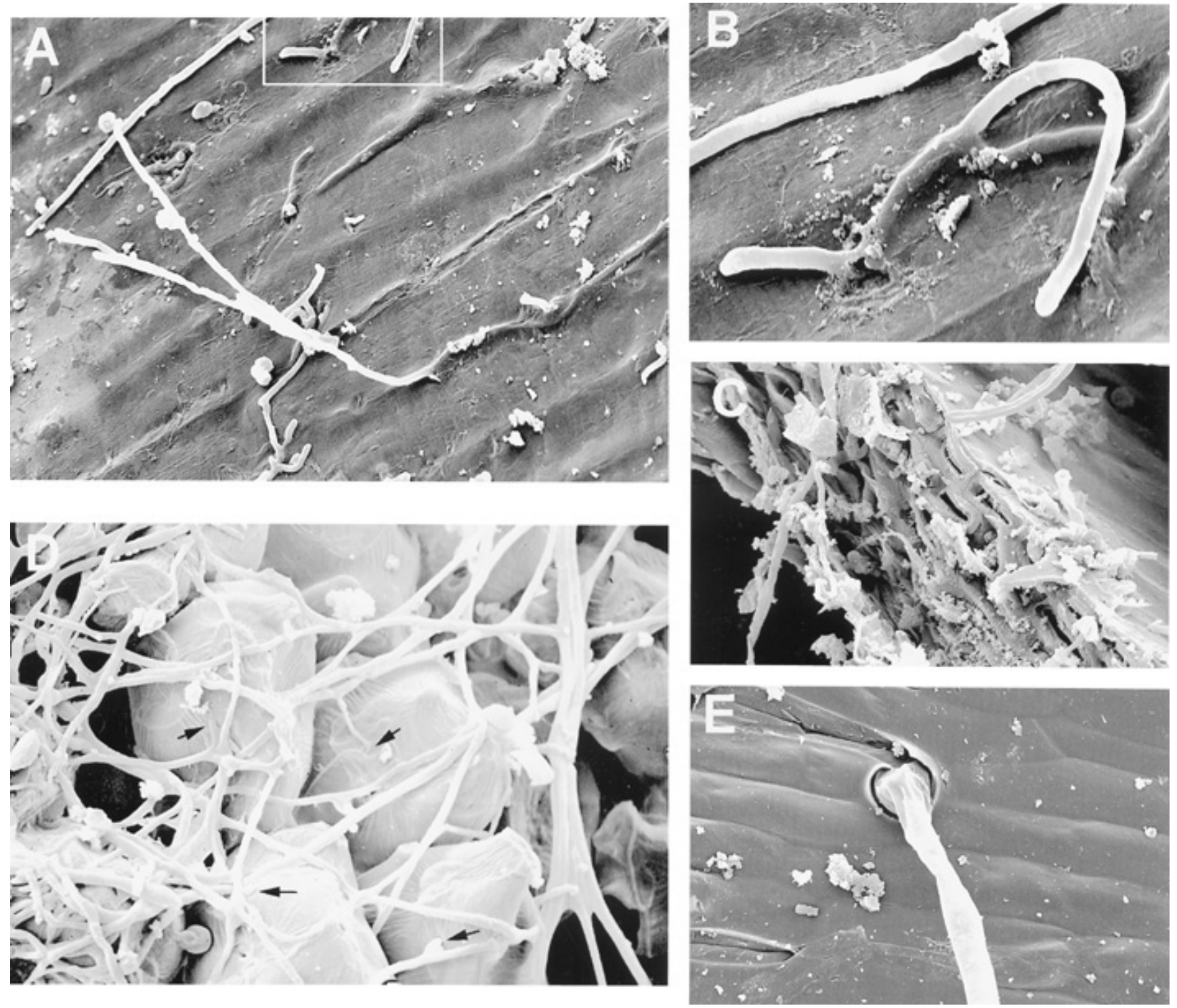

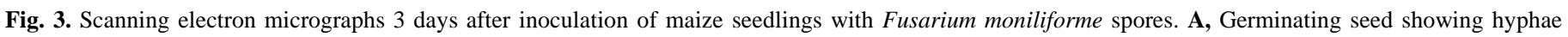

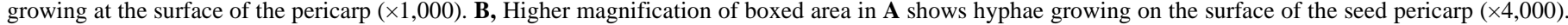

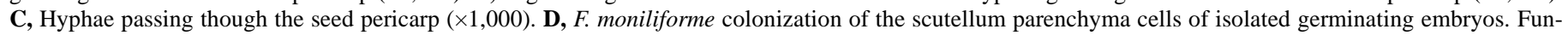

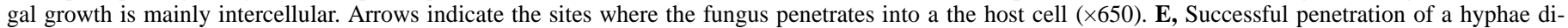
rectly through the epidermal cell of the radicle $(\times 1,000)$. 
ciation with a typical host defense response, the accumulation of the PRms protein. The maize PRms protein belongs to the PR-1 family of PR proteins. Even though members of this family of PR proteins have been identified in different plant species, their biological function in the plant defense response remains to be elucidated.

It is generally assumed that the initiation of the plant defense response depends on the recognition of molecular structures occur-
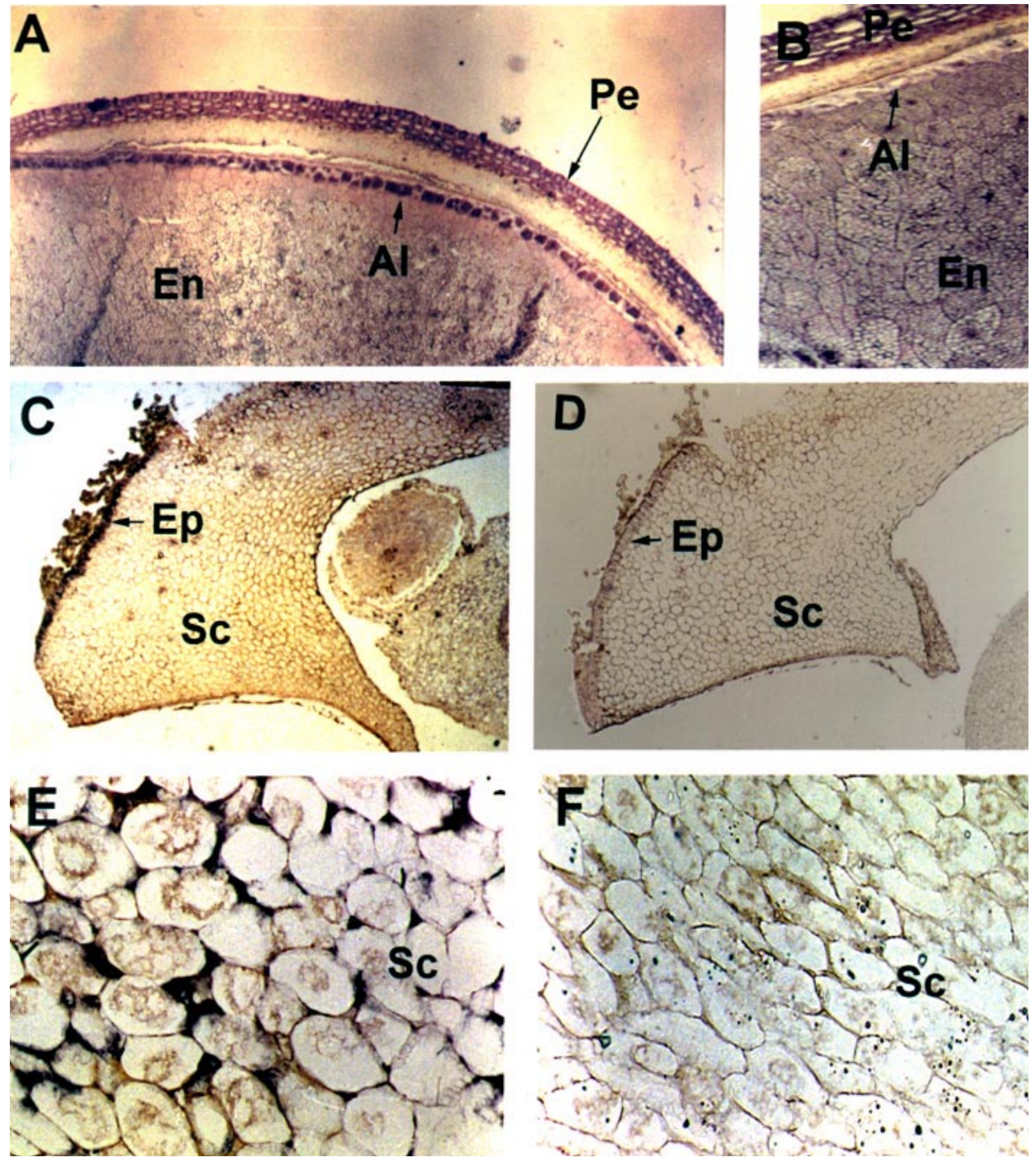

Fig. 4. Immunolocalization of PRms in tissue sections from Fusarium moniliforme-infected and sterile maize seed tissues. A and B, Transverse sections obtained from A, fungal-infected or B, sterile germinating seed incubated with the anti-PRms antiserum. Sections were prepared $48 \mathrm{~h}$ after inoculation. PRms accumulation in the aleurone layer cells of the infected seed is visible, as evidenced by the violet color $(\mathbf{A}, \times 240 ; \mathbf{B}, \times 400)$. Background signal is observed in the pericarp. Transverse sections obtained from $\mathbf{C}$, fungal-infected or $\mathbf{D}$, sterile isolated germinating embryos incubated with the anti-PRms antiserum. Sections were prepared $24 \mathrm{~h}$ after inoculation. This analysis reveals the accumulation of the PRms protein in the epithelial cells of the scutellum $(\mathbf{C}$ and D, $\times 240)$. E and $\mathbf{F}$, Transverse sections though the parenchyma cells of the scutellum, 5 to 10 cells from the epidermis incubated with $\mathbf{E}$, the anti-PRms or $\mathbf{F}$, the preimmune serum. Sections were prepared 5 days after inoculation. Discrete sites showing high concentrations of PRms-specific labeling randomly distributed between the parenchyma cells were detected $(\mathbf{E}, \times 750 ; \mathbf{F}, \times 640) . \mathrm{Al}=$ aleurone layer, End $=$ endosperm, $\mathrm{Ep}=$ epithelium, $\mathrm{Pe}=$ pericarp, and $\mathrm{Sc}=\mathrm{scutellum}$. 
ring in pathogens, also known as exogenous elicitors, by plasma membrane receptors $(2,12,30)$. Results here presented on the immunoblot analysis of protein extracts prepared from fungal-infected tissues revealed that the maize seedling is capable of perceiving signals, or elicitors, from a variety of fungal pathogens. Percep- tion of the pathogen, in turn, triggers this particular host response, the accumulation of the PRms protein. The various fungi assayed here differed in the composition of their corresponding cell walls, and all of them induced PRms accumulation. Thus, celluloseglucan cell wall-containing (Pythium spp.) and chitin-glucan cell
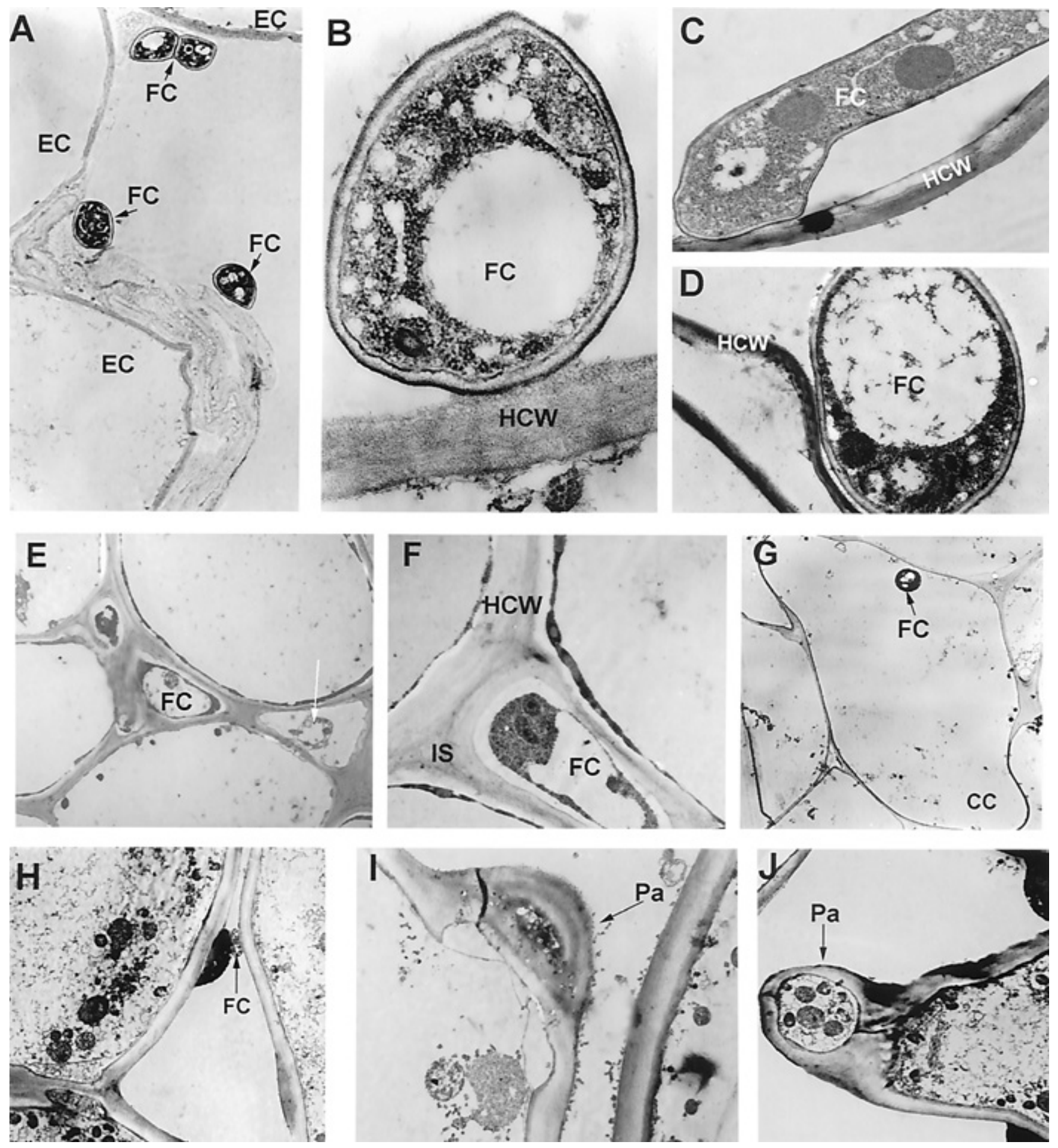

Fig. 5. Transmission electron micrographs of seedling tissues 3 days after inoculation with Fusarium moniliforme. Cytology of infection of A to G, the radicle and $\mathbf{H}$ to $\mathbf{~ J}$, scutellum tissues. A to $\mathbf{D}$, Fungal cells in close association with the epidermal cells. A, An amorphous matrix lining the epidermal walls and $\mathbf{D}$, distortion of the host cell wall at the contact site with a fungal cell were features frequently observed $(\mathbf{A}, \times 5,300 ; \mathbf{B}, \times 40,000 ; \mathbf{C}, \times 12,000 ; \mathbf{D}, \times 15,000)$. E to G, Hyphae invade the cortical area of the fungal-infected radicle. $\mathbf{E}$ and $\mathbf{F}$, Within a colonized intercellular space, deposition of materials forms a continuous layer between the host and fungal walls. G, A hyphae has penetrated a subepidermal cell of the infected radicle $(\mathbf{E}, \times 4,000 ; \mathbf{F}, \times 9,000 ; \mathbf{G}, \times 4,600)$. H, The fungus invades the scutellum mostly via the intercellular spaces. Note the deposition of material on the outer host wall surface with different electron density forming a hemispherical structure at the contact site with an invading pathogen $(\times 4,000)$. I and $\mathbf{J}$, Formation of papillae was a common host response. These papillae were heterogeneous in their structure. $\mathbf{J}$, During papillae formation, entrapment of cytoplasmic content occurred $(\mathbf{I}, \times 8,000 ; \mathbf{J}, \times 4,000)$. CC $=$ cortical cell, EC $=$ epidermal cell, $\mathrm{FC}=$ fungal cell, $\mathrm{HCW}=$ host cell wall, $\mathrm{IS}=$ intercellular space, and $\mathrm{Pa}=$ papilla. 
wall-containing (Fusarium, Penicillium, and Trichoderma species) fungi were assayed. Besides, there is no apparent correlation between the pathogenicity to maize seedlings of the different fungi and the level of PRms accumulation. Further work is required to determine whether there are active component(s) in the various fungi assayed in this work that act as elicitor(s) of PRms accumulation.

Examination of trypan blue-stained sections and SEM micrographs of $F$. moniliforme-infected maize tissues revealed penetration of the pathogen into the host tissues and fungal development via inter- and intracellular modes of growth. Immunohistochemical localization experiments revealed significant levels of PRms accumulation in those cell types that are the sites of immediate contact with the pathogen. This would be the case for the aleurone layer of the germinating seed or for the scutellum epithelial cells of isolated germinating embryos. In these specific cell types, a strong host response occurs, as judged by the observed accumulation of PRms. Presumably, the accumulation of high levels of defense proteins in cell types that are the first to establish contact with the pathogen would create a defensive barrier against fungal penetration. In addition, our ultrastructural studies revealed that fungal ingress into the host tissues was accompanied by pronounced

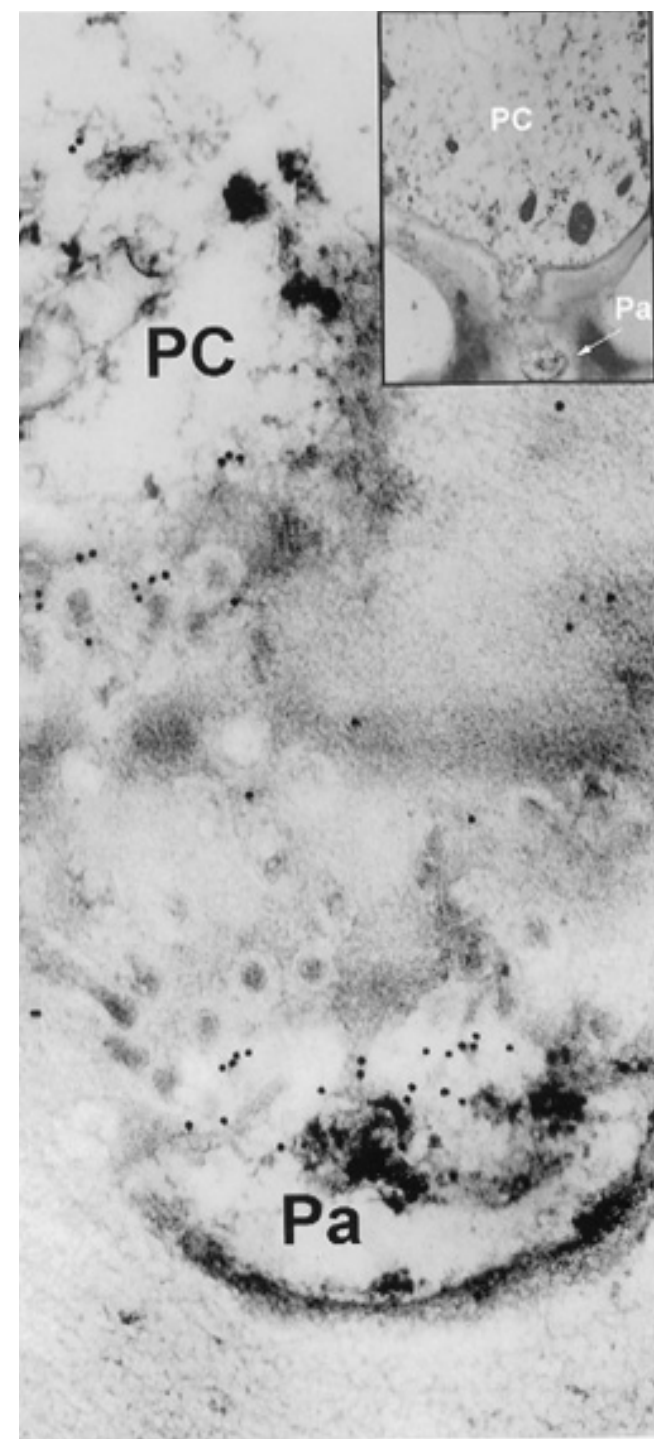

Fig. 6. Immunolocalization of PRms protein in a forming papilla of Fusarium moniliforme-infected seed tissues. Section showing a developing papillae in a parenchyma cell of the maize scutellum (inset). Incubation with the antiPRms antiserum revealed intense PRms-specific labeling within the forming papilla $(\times 50,000) . \mathrm{Pa}=$ papilla and $\mathrm{PC}=$ parenchyma cell. host cell alterations. One of the major host responses was the deposition of wall appositions on the outer cell wall surface at sites of attempted fungal entry. Another feature of the host response was the accumulation of materials and occlusion of the invaded intercellular spaces. Formation of papillae that varied greatly in size, shape, and structure was a typical reaction of the scutellar tissue. Entrapment of cytoplasmic material and vesicles, but no degeneration of the host protoplasm, occurs during papillae formation.

Although plant cells have long been known to react to fungal infection by papillae formation, very little information is currently available about papillae function and composition and the role that these structures play in disease resistance. It has been proposed that papillae might function in the formation of a mechanical barrier through which the pathogen must penetrate to gain access to the host cell cytoplasm. In agreement with this, the presence in papillae of glycoproteins, which are normally present in the cell walls of higher plants, such as hydroxyproline-rich glycoproteins has been reported $(3,31)$. As a part of our characterization of the maize defense response, we studied the composition of papillae using the immunological approach. Immunoelectron micrographs revealed PRms accumulation in forming papillae. This result then provides the first evidence that papillae formation and accumulation of defense proteins into these structures may be coordinated processes. Moreover, this phenomenon was observed at sites distant from the invading pathogen and without host cell degeneration. This finding indicates that scutellar cells are signaled to activate this defense response to hinder the penetration of the pathogen into the host tissue. Additionally, the accumulation of PRms in papillae provides evidence for the existence of a differential targeting of this protein in fungal-infected maize tissues. Thus, previous studies demonstrated that the PRms protein is targeted to the plasmodesmata in the fungal-infected maize radicle (28). Further work is now required to determine the molecular mechanisms responsible for this differential targeting of PRms in different tissues of the fungal-infected maize seedling.

Examination of $F$. moniliforme hyphae on the surface of the infected tissue by TEM showed various degrees of cell alteration. Furthermore, our immunocytochemical analysis of $F$. moniliformeinfected maize tissues revealed PRms-specific labeling in fungal cells showing cell alteration. PRms labeling was found to accumulate in clusters over the fungal cell wall. These findings suggest that PRms indeed might interact with fungal cells. Further experiments will be necessary to assess whether PRms has an antifungal activity, as it is the case for other members of the PR-1 family of PR proteins (29). The hypothesis that PRms might follow the activity or act in combination with other hydrolytic activities (i.e., chitinases and $\beta$-1,3-glucanases) to achieve a more complete disintegration of fungal cells should be taken into consideration. Related to this, the expression of chitinases and $\beta-1,3$-glucanases in this pathosystem was previously reported by our group (10). Finally, results presented in this study concerned not only the plant cell reaction to fungal invasion but also the pathogen action on the host cells. Fungi are known to excrete a great variety of enzymes, cellulolytic, pectolytic, proteolytic, and amylolytic, as well as cutinases. The combined action of these enzymes is able to degrade plant cell walls and the contents of the cells. Results presented in Figure 5J show that degradation of cell walls is observed in both fungal and host cell walls, indicating that both the host and the fungal cells are most likely producing "active" compounds directed to attack each other.

To summarize, a correlation has been found between infection of maize seeds by F. moniliforme and PRms accumulation. From results presented here, it appears that maize seedling tissues attacked by $F$. moniliforme are capable of developing different strategies to prevent massive colonization by the fungus. A first defensive line would consist of the accumulation of PRms and, most probably, other defense proteins in those cell types that are the first 

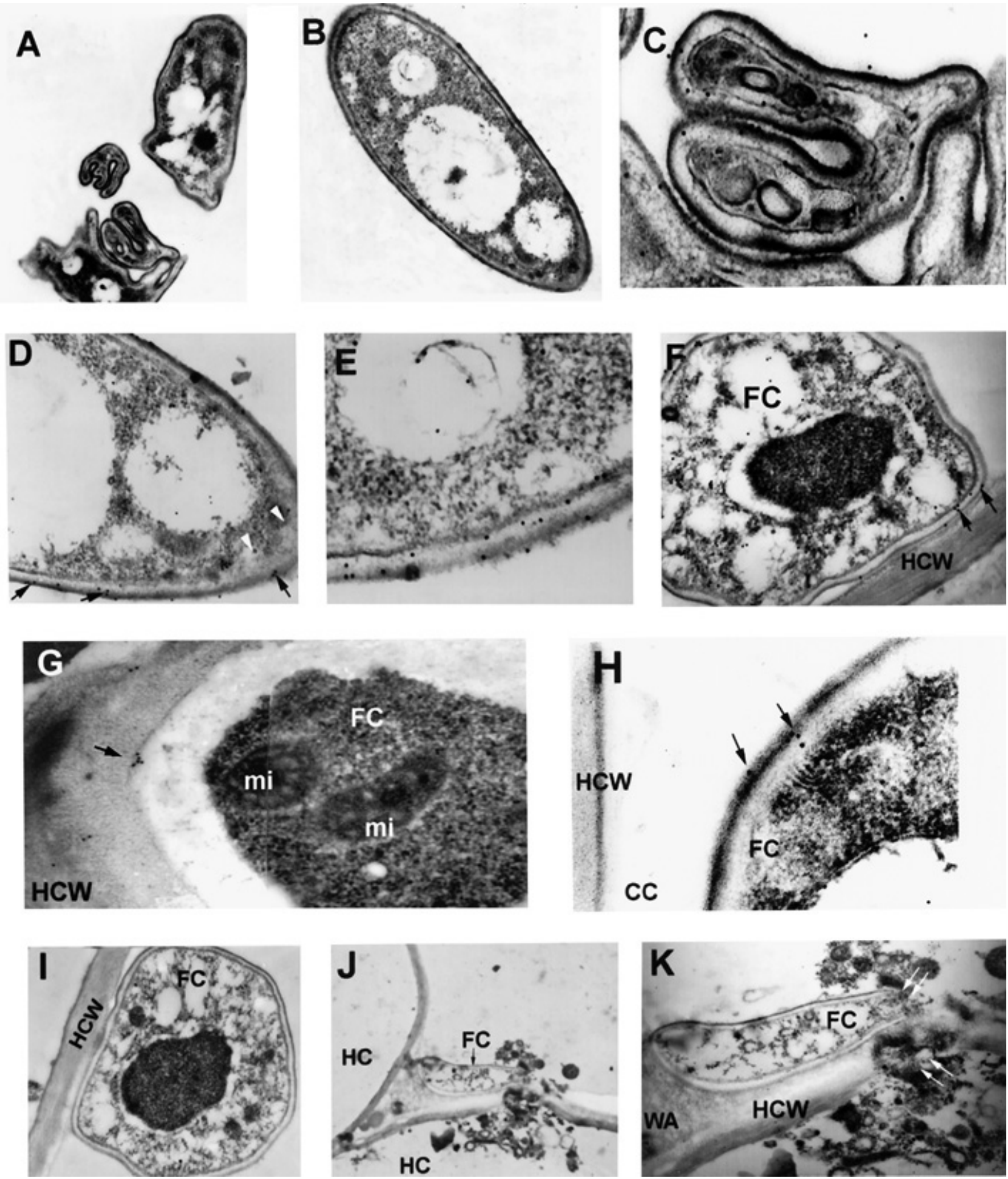

Fig. 7. Transmission electron micrographs of Fusarium moniliforme-infected maize tissues. Labeling with the anti-PRms antiserum. A and B, Fungal cells growing on the surface of the infected tissues $(\mathbf{A}, \times 15,000 ; \mathbf{B}, \times 20,000)$. C, Higher magnification of $\mathbf{A}(\times 53,000)$. D and E, Higher magnifications of $\mathbf{B}$. Fungal cells exhibit various degrees of alterations such as retraction of the plasmalemma from the fungal wall or diffuse appearance of the wall (D, white arrowheads). PRms labeling was associated to these abnormal hyphae, the wall of the fungal cell being densely labeled $(\mathbf{D}, \times 30,000 ; \mathbf{E}, \times 46,000)$. F, Section through a fungal cell attached to the host epidermal cell $(\times 33,000)$. G, Section through a fungal hypha invading an intercellular space $(\times 50,000)$. H, Section through a fungal hypha that has penetrated a cortical cell. Note that PRms labeling is mainly found as clusters over the fungal cell wall (F to $\mathbf{H}$, arrows) (H, $\times 40,000)$. I, Section of a fungal cell incubated with preimmune serum. No labeling is associated with the fungal cell $(\times 27,000)$. $\mathbf{J}$, In areas where the fungal cells where in close association with host cells, dissolution of the host and fungal cell walls at the contact sites and protoplasm leakage were obs erved $(\times 4,000)$. K, Higher magnification of $\mathbf{J}$. Arrows indicate wall degradation in both host and fungal cells $(\times 6,000)$. Cyt $=$ cytoplasm, $\mathrm{FC}=$ fungal cell, $\mathrm{HC}=$ host cell, $\mathrm{HCW}=$ host cell wall, $\mathrm{mi}=$ mitochondria, and $\mathrm{WA}=$ wall apposition . 
to contact the pathogen. Our study also revealed the presence of a large number of fungal cells with an abnormal shape that showed PRms-specific labeling. The observation that fungal cells in the proximity of the host epidermis showed various degrees of cell alteration might be indicative of a fungicidal environment. Further studies are, however, required to determine the precise biochemical function associated with the PRms protein. The accumulation of PRms and, most probably, other defense proteins in papillae at inner parts of the infected tissue would represent a second defensive line against fungal cells that have escaped the first barrier of the host defense response. These defense compounds would then come in direct contact with the pathogen in a highly concentrated form. Clearly, the expression of different defense strategies would result in a more efficient protection of the growing embryo against fungal pathogens. Taken together, the occurrence of PRms in cell types that are the first to establish contact with the pathogen, as well as in papillae and in association with fungal cell walls, suggest that PRms might have a function in the plant defense response.

\section{ACKNOWLEDGMENTS}

We thank the research facility used for electron microscopy studies, the Servei de Microscòpía Electronica (University of Barcelona, Barcelona, Spain). L. Cavallarin was a recipient of a predoctoral fellowship from the European Commission. This work was supported by Grant No. BIO970710 from Plan Nacional de Investigación y Desarrollo Tecnológico and was carried out within the framework of the Centre de Referència de Biotecnología (CERBA) from the Generalitat de Cataluña.

\section{LITERATURE CITED}

1. Alexander, D., Goodman, R. M., Gut-Rella, M., Glascock, C., Weymann, K., Friedrich, L., Maddox, D., Ahl-Goy, P., Luntz, T., Ward, E., and Ryals, J. 1993. Increased tolerance to two oomycete pathogens in transgenic tobacco expressing pathogenesis-related protein 1a. Proc. Natl. Acad. Sci. U.S.A. 90:7327-7331.

2. Baker, B., Zambryski, P., Staskawicz, B., and Dinesh-Kumar, S. P. 1997. Signaling in plant-microbe interactions. Science 276:726-732.

3. Benhamou, N., Mazau, D., Grenier, J., and Esquerré-Tugayé, M.-T. 1991. Time-course study of the accumulation of hydroxyproline-rich glycoproteins in root cells of susceptible and resistant tomato plants infected by Fusarium oxysporum f. sp. radicis-lycopersici. Planta 184:196208.

4. Bowles, D. J. 1990. Defense-related proteins in higher plants. Annu. Rev. Biochem. 59:873-907.

5. Bradford, M. 1976. A rapid and sensitive method for the quantification of microgram quantities of proteins utilizing the principle of protein-dyebinding. Anal. Biochem. 72:248-254.

6. Broglie, K., Chet, I., Holliday, M., Cressman, R., Diddle, P., Knowlton, S., Mauvais, C. J., and Broglie, R. 1991. Transgenic plants with enhanced resistance to the fungal pathogen Rhizoctonia solani. Science 254:11941197.

7. Bryngelsson, T., Sommer-Knudsen, J., Gregersen, P. L., Collinge, D. B., Ek, B., and Thordal-Christensen, H. 1994. Purification, characterization, and molecular cloning of basic PR-1-type pathogenesis-related proteins from barley. Mol. Plant-Microbe Interact. 7:267-275.

8. Casacuberta, J. M., Puigdoménech, P., and San Segundo, B. 1991. A gene coding for a basic pathogenesis-related protein from Zea mays. Molecular cloning and induction by a fungus (Fusarium moniliforme) in germinating maize seeds. Plant Mol. Biol. 16:527-536.

9. Cordero, M. J., Raventós, D., and San Segundo, B. 1992. Induction of PR proteins in germinating maize seeds infected with the fungus Fusarium moniliforme. Physiol. Mol. Plant Pathol. 41:189-200.

10. Cordero, M. J., Raventós, D., and San Segundo, B. 1994. Differential expression and induction of chitinases and $\beta$-1,3-glucanases in response to fungal infection during germination of maize seeds. Mol. Plant-Microbe Interact. 7:23-31.

11. Cordero, M. J., Raventós, D., and San Segundo, B. 1994. Expression of a maize proteinase inhibitor gene is induced in response to wounding and fungal infection. Systemic wound-response of a monocot gene. Plant J. 6:141-150

12. Dixon, R. A., Harrison, M. J., and Lamb, C. J. 1994. Early events in the activation of plant defense responses. Annu. Rev. Phytopathol. 32:479-501.

13. Flor, H. 1971. Current status of the gene-for-gene concept. Annu. Rev.
Phytopathol. 9:275-296.

14. Holley, R. N., Hamilton, P. B., and Goodman, M. M. 1989. Evaluation of tropical maize germ plasm for resistance to kernel colonization by $\mathrm{Fu}$ sarium moniliforme. Plant Dis. 73:578-580.

15. Jamet, E., and Fritig, B. 1986. Purification and characterization of 8 of the pathogenesis-related proteins in tobacco leaves reacting hypersensitively to tobacco mosaic virus. Plant Mol. Biol. 6:69-80.

16. Jongedijk, E., Tigelaar, H., van Roekel, J. S. C., Bres-Vloemans, S. A., Dekker, I., van den Elzen, P. J. M., Cornelissen, B. J. C., and Melchers, L. 1995. Synergistic activity of chitinases and $\beta-1,3$-glucanases enhances fungal resistance in transgenic tomato plants. Euphytica 85: 173-180.

17. Kauffmann, S., Legrand, M., Geoffroy, P., and Fritig, B. 1987. Biological function of "pathogenesis-related" proteins: Four PR proteins of tobacco have 1,3-beta-glucanase activity. EMBO (Eur. Mol. Biol. Organ.) J. 6:3209-3212.

18. Keogh, R. C., Deverall, B. J., and McLeod, S. 1980. Comparison of histological and physiological responses to Phakopsora parachyrhizi in resistant and susceptible soybean. Trans. Br. Mycol. Soc. 74:329-333.

19. King, S. B., and Scott, G. E. 1981. Genotypic differences in maize to kernel infection by Fusarium moniliforme. Phytopathology 71:1245-1247.

20. Laemmli, U. K. 1970. Cleavage of structural proteins during the assembly of the head of bacteriophage T4. Nature 277:680-685.

21. Legrand, M., Kauffmann, S., Geoffroy, P., and Fritig, B. 1987. Biological function of pathogenesis-related proteins: Four tobacco pathogenesis-related proteins are chitinases. Proc. Natl. Acad. Sci. U.S.A. 84:6750-6754.

22. Linthorst, H. J. M. 1991. Pathogenesis-related proteins of plants. Crit. Rev. Plant Sci. 10:123-150.

23. Liu, D., Raghothama, K. G., Hasegawa, P. M., and Bressan, R. A. 1994. Osmotin overexpression in potato delays development of disease symptoms. Proc. Natl. Acad. Sci. U.S.A. 91:1888-1892.

24. Logrieco, A., Bottalico, A., and Ricci, V. 1990. Occurrence of Fusarium species and their mycotoxins in cereal grains from some Mediterranean countries. Phytopathol. Mediterr. 29:81-89.

25. Lucas, J., Camacho-Henriquez, A., Lottspeich, F., Henschen, A., and Sanger, H. L. 1985. Amino acid sequence of the "pathogenesis-related" leaf protein p14 from viroid-infected tomato reveals a new type of structurally unfamiliar proteins. EMBO (Eur. Mol. Biol. Organ.) J. 4:2745-2749.

26. Matsuoka, M., and Ohashi, Y. 1986. Induction of pathogenesis-related proteins in tobacco leaves. Plant Physiol. 80:505-510.

27. Metzler, M. C., Cutt, J. R., and Klessig, D. F. 1991. Isolation and characterization of a gene encoding a PR-1 like protein from Arabidopsis thaliana. Plant Physiol. 96:346-348.

28. Murillo, I., Cavallarin, L., and San Segundo, B. 1997. The maize pathogenesis-related PRms protein localizes to plasmodesmata in maize radicles. Plant Cell 9:145-156.

29. Niderman, T., Genetet, I., Bruyère, T., Gees, R., Stintzi, A., Legrand, M., Fritig, B., and Mösinger, E. 1995. Pathogenesis-related PR-1 proteins are antifungal. Plant Physiol. 108:17-27.

30. Nürnberger, T., and Nennstiel, D. 1998. Fungal peptide elicitors: Signals mediating pathogen recognition in plants. Z. Naturforsch. Sect. C Biosci. 53:141-150.

31. O'Connell, R. J., Brown, I. R., Mansfield, J. W., Bayley, J. A., Mazau, D., Rumeau, D., and Esquerré-Tugayé, M.-T. 1990. Immunocytochemical localization of hydroxyproline-rich glycoproteins accumulating in melon and bean at sites of resistance to bacteria and fungi. Mol. Plant-Microbe Interact. 3:33-40.

32. Raventós, D., Cordero, M. J., and San Segundo, B. 1994. Fungal-induced synthesis of PR proteins in germinating maize embryos. Physiol. Mol. Plant Pathol. 45:349-358.

33. Raventós, D., Jensen, A. B., Rask, M.-B., Casacuberta, J. M., Mundy, J., and San Segundo, B. 1995. A 20 bp cis-acting element is both necessary and sufficient to mediate elicitor response of a maize PRms gene. Plant J. 7:147-155.

34. Schlumbaum, A., Mauch, F., Vogeli, U., and Boller, T. 1986. Plant chitinases are potent inhibitors of fungal growth. Nature 324:365-367.

35. Sela-Buurlage, M. B., Ponstein, A. S., Bres-Vloemans, S. A. B., Melchers, L. S., van den Elxen, P. J. M., and Cornelissen, B. J. C. 1993. Only specific tobacco (Nicotiana tabacum) chitinases and beta-1,3-glucanases exhibit antifungal activity. Plant Physiol. 101:857-863.

36. Shidu, G. S. 1988. Gibberella spp., pathogens of many crop species. Pages 159-167 in: Advances in Plant Pathology. Vol. 6. D. S. Ingram and P. H. Williams, eds. Academic Press, San Diego, CA.

37. Somssich, I. E., and Hahlbrock, K. 1998. Pathogen defence in plants-A complex paradigm of biological complexity. Trends Plant Sci. 3:86-90.

38. Staskawicz, B. J., Ausubel, M., Baker, B., Ellis, J. G., and Jones, D. G. 1995. Molecular genetics of plant disease resistance. Science 268:661-667.

39. Towbin, H., Staehelin, T., and Gordon, J. 1979. Electrophoretic transfer of proteins from polyacrylamide gels to nitrocellulose sheets: Procedures 
and some applications. Proc. Natl. Acad. Sci. U.S.A. 76:4350-4354.

40. Uknes, S., Mauch-Mani, B., Moyer, M., Potter, S., Williams, S., Dincher, S., Chandler, D., Slusarenko, A., Ward, E., and Ryals, J. 1992. Acquired resistance in Arabidopsis. Plant Cell 4:645-656.

41. van Loon, L. C. 1985. Pathogenesis-related proteins. Plant Mol. Biol. 4: 111-116.

42. Vera, P., Hernández-Yago, J., and Conejero, V. 1988. Immunocytochemical localization of the major pathogenesis-related (PR) protein of tomato plants. Plant Sci. 55:223-230.

43. Zhu, Q., Dröge-Laser, W., Dixon, R. A., and Lamb, C. 1996. Transcriptional activation of plant defense genes. Curr. Opin. Genet. Develop. 6: 624-630.

44. Zhu, Q., Maher, E. A., Masoud, S., Dixon, R. A., and Lamb, C. J. 1994. Enhanced protection against fungal attack by constitutive co-expression of chitinase and glucanase genes in transgenic tobacco. Biotechnology 12:807-812. 